\title{
Sexually Dimorphic Risk Mitigation Strategies in Rats
}

\author{
Blake A. Pellman, ${ }^{1}$ Bryan P. Schuessler, ${ }^{1}$ - Mohini Tellakat, ${ }^{2}$ and ${ }^{\circledR}$ Jeansok J. Kim ${ }^{1,3}$
}

DOI:http://dx.doi.org/10.1523/ENEURO.0288-16.2017

${ }^{1}$ Department of Psychology, University of Washington, Seattle, Washington 98195-1525, ${ }^{2}$ Department of Psychology, University of Texas at Austin, Austin, Texas 78712, and ${ }^{3}$ Program in Neuroscience, University of Washington, Seattle, Washington 98195-1525

\begin{abstract}
The scientific understanding of fear and anxiety-in both normal and pathological forms-is presently limited by a predominance of studies that use male animals and Pavlovian fear conditioning-centered paradigms that restrict and assess specific behaviors (e.g., freezing) over brief sampling periods and overlook the broader contributions of the spatiotemporal context to an animal's behavioral responses to threats. Here, we use a risky "closed economy" system, in which the need to acquire food and water and the need to avoid threats are simultaneously integrated into the lives of rats, to examine sex differences in mitigating threat risk while foraging. Rats lived for an extended period ( $\sim 2$ months) in enlarged chambers that consisted of a safe, bedded nest and a risky foraging area where footshocks could be delivered unpredictably. We observed that male and female rats used different strategies for responding to the threat of footshock. Whereas male rats increased the size of meals consumed to reduce the overall time spent foraging, female rats sacrificed their metabolic needs in order to avoid shocks. Ovarian hormone fluctuations were shown to exert slight but reliable rhythmic effects on risky decision-making in gonadally intact female rats. However, this did not produce significant differences in approach-avoidance trade-offs between ovariectomized and intact female groups, suggesting that male-female sex differences are not due to the activational effects of gonadal hormones but, rather, are likely to be organized during early development.
\end{abstract}

Key words: anxiety; decision-making; fear; foraging behavior; sex differences

\section{Significance Statement}

The National Institutes of Health $(\mathrm{NIH})$ has recently mandated that all $\mathrm{NIH}$-funded research must include balanced samples of each sex, but the initiative does little to address the reasons why researchers have avoided including female animals in their studies, which includes the perceived difficulty and high cost of controlling for estrous cycle-related variability and its effect on behavior. Here, we use a longitudinal design to measure sex differences and the temporal variability of ovarian hormones on fear, anxiety, and risky decision-making continuously, and demonstrate functional differences in fear and anxiety behaviors between male and female rats that are independent of estrous cycle fluctuations.

\section{Introduction}

Anxiety- and fear-related disorders are among the most common mental illnesses, usually afflicting women significantly more than men (Kessler et al., 2005), and the United States spends millions of dollars each year for

Received September 23, 2016; accepted January 20, 2017; First published January 27, 2017.

The authors declare no competing financial interests. researching the basic mechanisms of normal and pathological fear and anxiety (Institute of Medicine, 2014). Typical animal models of anxiety- and fear-related disorders predominately use behavioral paradigms, such as Pavlovian fear conditioning, and open field and elevated plus 


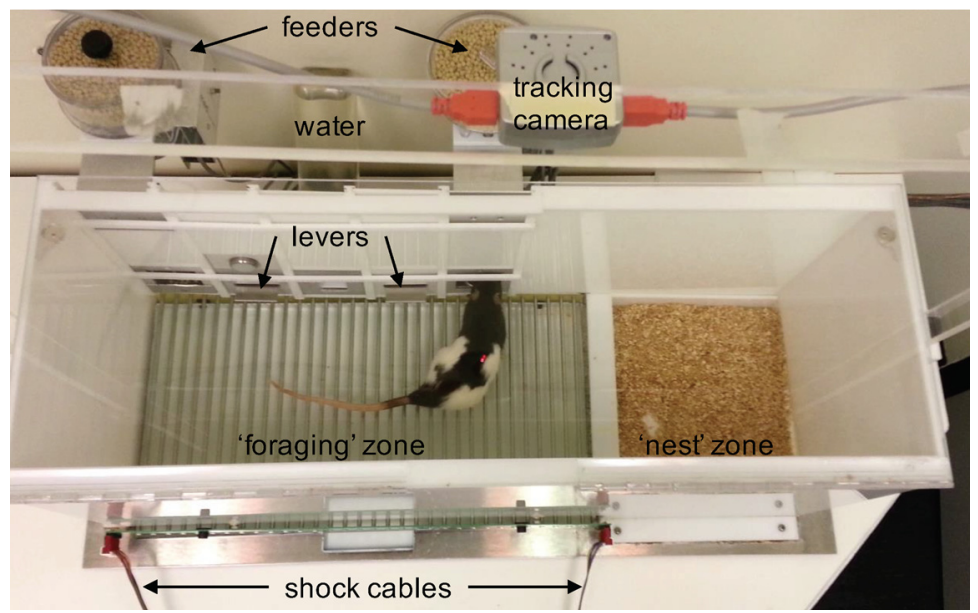

Figure 1. Experimental apparatus and design of the closed economy. Photograph of a closed economy box. Measurements of lever presses, food dispensed, water bottle licks, footshocks delivered and received, and locomotor tracking and spatial position via overhead-mounted tracking camera were coordinated by ANY-maze I/O interface and software (RRID:SCR_014289). Gonadally intact male $(n=8)$ and female $(n=12)$ and OVX female rats $(n=8)$ rats were housed in the closed economy boxes upon arrival and were shaped to respond on an FR25-CRF schedule over $\sim 12 \mathrm{~d}$, followed by $14 \mathrm{~d}$ of baseline measurement, $14 \mathrm{~d}$ of shock, and $14 \mathrm{~d}$ of extinction (no shock) conditions.

maze tests, which are designed to assess a specific behavior (e.g., freezing) during brief sampling periods (Davis, 1992; Lissek et al., 2005; Milad and Quirk, 2012; Jones and Monfils, 2016). While these paradigms to study fear and anxiety have been useful in generating much of the knowledge we have on the mechanisms and influence of various treatments (e.g., drugs, stress, social interactions), all such studies are similarly limited in that they examine behavior in settings that restrict the natural repertoire of behaviors (largely to simplify analysis) and sample behavior over a short duration, which ignores the longer-scale spatiotemporal integration of information that animals rely on to function in natural environments.

Compounding these limitations, there is a lack of representation of female animals in fear and anxiety research, caused in part by the perceived difficulty and cost in controlling the variability associated with female animals' reproductive cycles (Zucker and Beery, 2010; Prendergast et al., 2014; Becker et al., 2016). The estrous cycle of a female rat, which is typically divided into four primary "stages" (proestrus, estrus, metestrus, and diestrus), has been linked to physiological fluctuations in synapse density in the hippocampus, amygdala, and prefrontal cortex (Woolley and McEwen, 1992; Shansky et al., 2004; RasiaFilho et al., 2012), neurogenesis in the hippocampus

This study was supported by National Institutes of Health/National Institute of Mental Health Grant MH-099073 (J.J.K.).

Acknowledgments: We thank Jacky Chan, Kisho Fukuoka, and Patricia Colosi for assistance in the experiment.

Correspondence should be addressed to Jeansok J. Kim; UW Box 351525, University of Washington, Seattle, WA 98195-1525. E-mail: jeansokk@u. washington.edu.

DOI:http://dx.doi.org/10.1523/ENEURO.0288-16.2017

Copyright () 2017 Pellman et al.

This is an open-access article distributed under the terms of the Creative Commons Attribution 4.0 International, which permits unrestricted use, distribution and reproduction in any medium provided that the original work is properly attributed.
(Pawluski et al., 2009), and behavioral variation in elevated plus-maze (Marcondes et al., 2001), open field (Frye and Walf, 2002), fear conditioning (Markus and Zecevic, 1997; Gupta et al., 2001), and fear extinction tests (Milad et al., 2009). Completely controlling for such fluctuations systematically would require testing animals in all test stageestrous phase combinations, demanding greater animal numbers and substantially increasing costs. Nonetheless, brief temporal sampling and the lack of female representation have likely led to a narrow view of fear and anxiety processes, and the extent to which animal models of these processes generalize to those of humans is questionable. Indeed, studies have found that male rats show greater fear responses than female rats (Maren et al., 1994; Markus and Zecevic, 1997), which does not parallel either the findings that women have higher incidences of and suffer more from anxiety- and fear-related disorders than men (Brown et al., 1992; McLean and Anderson, 2009), or that, even under normal conditions, women report experiencing stronger fears than men (Geer, 1965; Ollendick et al., 1989; Gullone, 2000).

The present study used a longitudinal, risky "closed economy" system (Hursh, 1980; Fanselow and Lester, 1988; Helmstetter and Fanselow, 1993; Kim et al., 2014; Pellman et al., 2015) to investigate sex differences and the activational role of ovarian hormones in fear and anxiety behaviors in rats. The risky closed economy system attempts to model an approach-avoidance conflict ostensibly shared by all species: decisions to explore and forage for resources, such as food and water, must be balanced by decisions to avoid potential risks and the threat of predation (Lima and Dill, 1990). This was modeled by housing rats in a dynamic environment that consisted of a safe, bedded nest area and a risky foraging area that had to be entered in order to obtain food and water and where footshocks could be delivered unpredictably (Fig. 1). It was hypothesized that female rats will 
be more reactive to the shock condition, in terms of foraging and avoidance behavior, compared with male rats. Furthermore, female rats will exhibit rhythmic variation in their risk-taking behaviors related to the fluctuations of ovarian hormones that will not be observed in male or ovariectomized female rats.

\section{Materials and Methods}

\section{Subjects}

Experimentally naive, gonadally intact male $(n=8)$ and female $(n=12)$ and ovariectomized (OVX) female $(n=8)$ Long-Evans rats (catalog \#2308852, RGD; RRID: RGD_2308852) initially 7-8 weeks of age were individually housed in eight closed economy chambers (Fig. 1) distributed between two separate rooms within the Department of Psychology at the University of Washington (accredited by the Association for Assessment and Accreditation of Laboratory Animal Care). Animals were tested in cohorts of eight, with experimental groups counterbalanced between the two rooms, and male and female rats within each cohort were kept in separate rooms. Ovariectomy surgeries were performed by Charles River Laboratories (RRID:SCR_003792) the day prior to shipment. All animal experiments were conducted in compliance with the National Institutes of Health Guide for the Care and Use of Laboratory Animals and were reviewed and approved by the University of Washington Institutional Animal Care and Use Committee.

\section{Closed economy task}

The closed economy dimensions were $74.3 \times 25.4 \times$ $33 \mathrm{~cm}$ (length $\times$ width $\times$ height) and consisted of a "nest" $(20.3 \times 25.4 \mathrm{~cm})$ and a "foraging arena" $(54 \times 25.4 \mathrm{~cm})$. The nest floor was covered with sawdust, while the floor of the foraging arena was composed of 32 stainless steel rods $(4.5 \mathrm{~mm}$ diameter) wired to a precision animal shocker (Coulbourn Instruments) for delivery of footshocks. A camera (Fire-I B/W Board camera; Unibrain) was mounted above each closed economy chamber and connected to a computer for tracking animal activity via ANY-maze software (RRID:SCR_014289), which also measured the activation of the food levers and dispensers (Med Associates) and the shock generator connected to an ANY-maze Interface (AMi; Stoelting). Forty-five milligram grain-based pellets for rodents (catalog \#F0165, Bio-Serv) were used for food. White noise (70 dB) generated by the ANY-maze software was continuously played through computer speakers throughout the experiment to obscure external noises.

After arrival, animals were given 12-14 d to acclimatize to the chambers and light cycle (12 h light/dark cycle), during which time they were shaped to press either of two levers 25 times initially to gain access to a continuous reinforcement schedule [fixed ratio 25-continuous reinforcement (FR25-CRF)], which was reset if $1 \mathrm{~min}$ had passed since the last lever press. The FR threshold was doubled every 2 d (except FR16 was increased to FR25) until stable lever pressing at the FR25 threshold was achieved. After 14 baseline days ("Baseline"), all of the animals were exposed to $14 \mathrm{~d}$ of unsignaled, pseudoran- dom footshocks (0.8 mA; 2 shocks/h; "Shock"). These shock parameters were chosen to maximize the changes in meal patterns and foraging strategies without creating an overly aversive environment that inhibits foraging altogether (Helmstetter and Fanselow, 1993). If the animal was in the foraging area when ANY-maze triggered the footshock, the shock continued for up to $10 \mathrm{~s}$ or until the animal escaped to the nest. If the animal was in the nest at the time the program generated the footshock, it terminated instantaneously. Animals were removed from the closed economy chambers and housed individually in a separate vivarium (also within the Department of Psychology at the University of Washington and accredited by the Association for Assessment and Accreditation of Laboratory Animal Care) during the last hour of the light phase [zeitgeber time 11 (ZT11) to ZT12] every 1-2 d so the chambers could be cleaned, the food and water replaced, and the animals weighed. They were provided access only to water in their temporary cages during this time.

\section{Estrous cycle monitoring}

Estrous phase was determined daily via vaginal lavage (Marcondes et al., 2002) in a subset of female rats $(n=4)$. Rats were brought into a separate room individually and handled momentarily, then were held in place by hand, and a pipette filled with $10 \mu$ l of $0.9 \%$ saline solution was gently and shallowly inserted into the vagina. The saline was washed in and drawn out, and was immediately placed on slides for cytological examination under a light microscope. Furthermore, OVX female rats were confirmed to lack a functioning estrous cycle by monitoring vaginal cytology for a week at the end of the experiment, which was characterized by a lack of change in cytology across days (Monies and Luque, 1988).

\section{Statistical analyses}

All data are presented as the mean \pm SEM. The data from the closed economy experiment were analyzed using mixed-factorial ANOVAs on the daily means, except where noted, with the within-subjects factor of experimental condition (baseline, shock, or extinction) and the between-subjects factor of sex. In cases where the assumption of sphericity was violated (Mauchly's test), Greenhouse-Geisser-corrected degrees of freedom were used. In cases where Levene's test for equality of variance was significant, Kruskal-Wallis tests were used to test for group differences within each condition independently. Bonferroni's test or Dunnett's T3-adjusted (for samples with unequal variances), two-tailed, paired-samples $t$ tests or independent $t$ tests were used for post hoc tests where noted. To determine a discrete "darting episode," ANY-maze was programmed to automatically detect movement speed that exceeded $23.5 \mathrm{~cm} / \mathrm{s}$, and movement speed had to decrease below $11.8 \mathrm{~cm} / \mathrm{s}$ before another darting episode was counted. To analyze estrous cycle-related fluctuation of locomotor activity in the closed economy, the apparatus-wide activity of rats (distance traveled, in meters) was summed in $1 \mathrm{~h}$ time bins and broken down into its component frequencies using fast Fourier transforms (FFT). The magnitudes of the frequencies in the 3-5 d range were used to test for statis- 

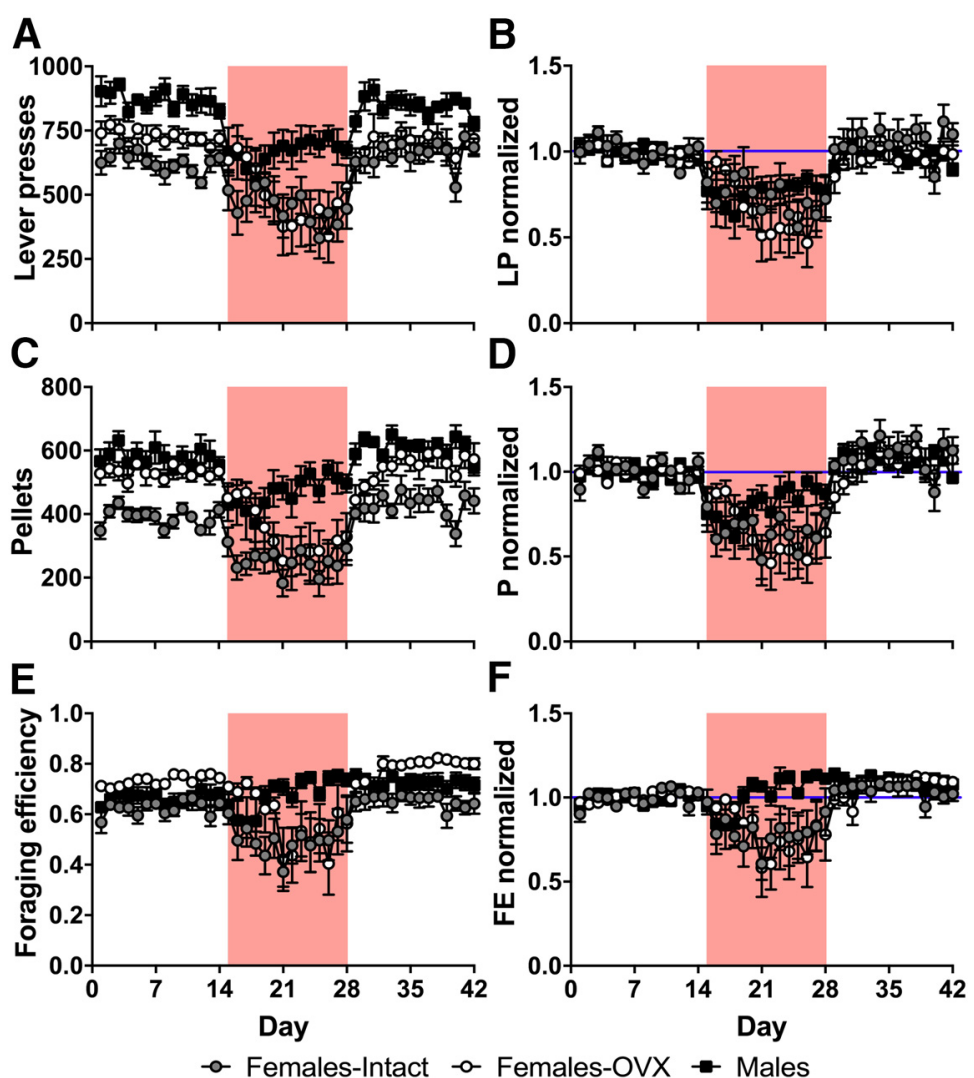

Figure 2. Sex differences and effects of ovariectomy and footshocks on foraging behaviors. $\boldsymbol{A}, \boldsymbol{B}$, Mean daily $(\boldsymbol{A})$ and normalized $(\boldsymbol{B}$; percentage of baseline average) number of lever presses (LPs) across both levers. $\boldsymbol{C}, \boldsymbol{D}$, mean daily (C) and normalized (D) number of pellets dispensed $(\mathrm{P})$ across both dispensers. $\boldsymbol{E}, \boldsymbol{F}$, mean daily $(\boldsymbol{E})$ and normalized $(\boldsymbol{F})$ foraging efficiency (pellets/lever press; FE). Gray circles represent intact female rats $(n=8)$, open circles represent OVX female rats $(n=8)$, and black squares represent male rats $(n=8)$. Red background denotes shock period. All data represent the mean \pm SEM.

tically significant sex differences using independent, onetailed $t$ tests. The appropriate group size $(n=4)$ for estrous cycle monitoring was determined by a power analysis (G*Power 3.1; RRID:SCR_013726), using an $\alpha$ of 0.05 , power of 0.80 , and an effect size (Cohen's f) of 0.50, which was based on findings from previous studies examining the effect of estrous cycle on anxiety-related behaviors (Diaz-Veliz et al., 1989; Mora et al., 1996). Analyses were performed with SPSS 19 (RRID:SCR_002865), and graphs were generated with GraphPad Prism 7.0 (RRID:SCR_002798).

\section{Results}

Gonadally intact, adult male $(n=8)$ and female $(n=12)$ rats and OVX adult female rats $(n=8)$ were housed individually in closed economy chambers (Fig. 1) upon arrival and maintained on a $12 \mathrm{~h}$ light/dark cycle. Subsequently, all animals were shaped to a FR25-CRF food schedule on either of two levers (i.e., after 25 lever presses, each lever press produced one pellet). These contingencies were reset if $1 \mathrm{~min}$ elapsed between any lever presses. Once stable responding had been reached, baseline measurements continued for $14 \mathrm{~d}$ (Baseline), followed by a $14 \mathrm{~d}$ period of pseudorandom, unpredictable footshocks delivered to the foraging area $(\sim 2 / \mathrm{h}$; Shock), and ending with a $14 \mathrm{~d}$ period where footshocks were terminated ("Extinction").
During baseline, male rats pressed levers at higher rates than both intact and OVX female rats, which did not differ from each other (Fig. 2A; group: $F_{(2,21)}=19.28, p=$ 0.000018; condition: $F_{(1.44,30.27)}=27.82, p=0.000001$, df adjusted; condition $*$ group: $F_{(2.88,30.27)}=0.26, p=0.85$, df adjusted; post hoc tests: males vs intact: $p=0.000017$; males vs OVX: $p=0.00088$; intact vs OVX: $p=0.32$, Bonferroni corrected). During the shock condition, although males continued lever pressing more than the females, all groups reduced lever pressing by a similar degree, and lever pressing quickly recovered to baseline levels during extinction (Fig. 2B; group: $F_{(2,21)}=0.68, p=$ 0.52; condition: $F_{(1.47,30.93)}=27.45, p \stackrel{0.000001, \mathrm{df}}{=}$ adjusted; condition*group: $F_{(2.95,30.93)}=0.46, p=0.71$, df adjusted). Almost all animals exclusively preferred one of the two levers, and this preference did not change appreciably across conditions. During baseline, male rats obtained significantly more pellets than intact females, but not OVX females (Fig. 2C; group: $F_{(2,21)}=21.78, p=$ 0.000008; condition: $F_{(1.31,27.40)}=40.71, p=1.28 \mathrm{E}-7$, df adjusted; condition $*$ group: $F_{(2.61,27.40)}=0.74, p=0.52$, df adjusted; post hoc tests: males vs intact: $p=0.00018$; males vs OVX: $p=0.091$; intact vs OVX: $p=0.0012$, Dunnett T3 corrected), and there were no significant differences between groups in the change in the number of pellets acquired during shock and extinction conditions 

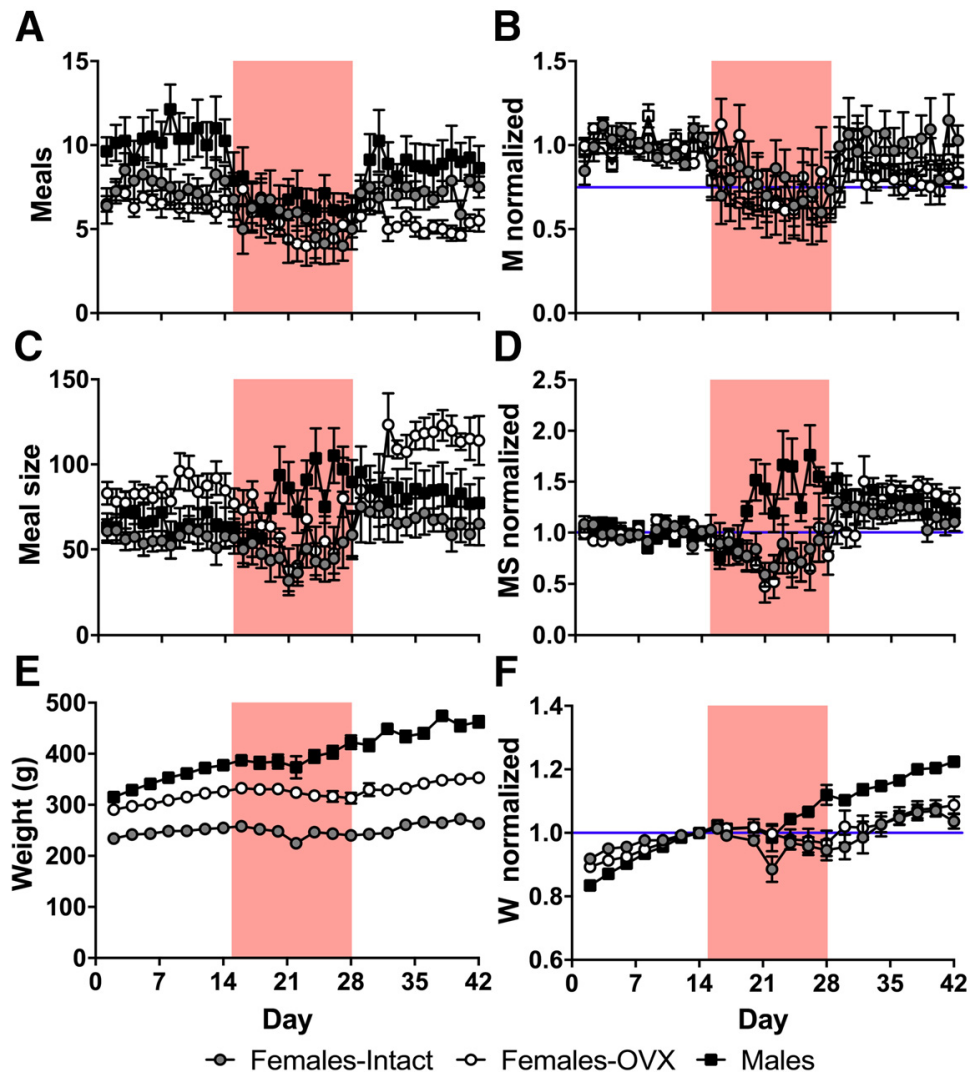

Figure 3. Sex differences and effects of ovariectomy and footshocks on meal patterns and body weight. $\boldsymbol{A}, \boldsymbol{B}$, Mean daily $(\boldsymbol{A})$ and normalized ( $\boldsymbol{B}$; percentage of baseline average) number of discrete meals obtained (FR25 threshold reached; M) across both levers. $\boldsymbol{C}, \boldsymbol{D}$, mean daily $(\boldsymbol{C})$ and normalized $(\boldsymbol{D})$ meal sizes (pellets/meal; MS) across both levers. $\boldsymbol{E}, \boldsymbol{F}$, The $2 \mathrm{~d}$ mean $(\boldsymbol{E})$ and normalized $(\boldsymbol{F}$; percentage of last baseline $2 \mathrm{~d}$ mean) body weight (in grams; W). Gray circles represent intact female rats $(n=8)$, open circles represent OVX female rats $(n=8)$, and black squares represent male rats $(n=8)$. Red background denotes shock period. All data represent the mean \pm SEM.

compared with baseline (Fig. 2D; group: $F_{(2,21)}=1.52, p=$ 0.24; condition: $F_{(1.29,26.98)}=41.31, p=1.36 \mathrm{E}-7$, df adjusted; condition*group: $F_{(2.57,26.98)}=1.09, p=0.36$, df adjusted). It is interesting to note that, although intact and OVX females pressed the levers at similar rates, OVX females were able to obtain significantly more food than intact females. Because obtaining pellets depends not just on lever pressing, but also on specifically uninterrupted lever pressing after reaching the FR25 threshold, a measure of "foraging efficiency" (pellets dispensed/lever presses) was created to estimate the proportion of lever presses that resulted in food pellets. Figure 2, $E$ and $F$, indicates that OVX females were significantly more efficient at obtaining pellets than intact females during the baseline and extinction periods (group: $F_{(2,21)}=6.56, p=$ 0.0061 ; condition: $F_{(1.20,25.20)}=18.78, p=0.00010$, df adjusted; condition*group: $F_{(2.40,25.20)}=3.21, p=0.050$, df adjusted; post hoc tests: Baseline: males vs intact, $p=$ 0.60 ; males vs OVX, $p=0.12$; intact vs OVX, $p=0.0055$; Shock: males vs intact, $p=0.036$; males vs OVX, $p=$ 0.45 ; intact vs OVX, $p=0.66$; Extinction: males vs intact, $p=0.11$; males vs OVX, $p=0.27$; intact vs OVX, $p=$ 0.002 , Dunnett T3 corrected), but not during shock, where intact and OVX female rats experienced a similar reduction in foraging efficiency while male rats were largely able to maintain their baseline foraging efficiency (group: Shock: $\chi^{2}{ }_{2}=7.66, p=0.022$, Extinction: $\chi^{2}{ }_{2}=0.56, p=$ 0.76 , Kruskal-Wallis tests; condition: $F_{(1.24,26.10)}=18.34$, $p=0.000094$, df adjusted; post hoc tests: Shock: males vs intact, $p=0.048$; males vs OVX, $p=0.099$; intact vs OVX, $p=1.00$, Dunnett T3 corrected). While males tended to obtain meals more frequently (Fig. $3 A$; group: $F_{(2.21)}=4.20, p=0.029$; condition: $F_{(2,42)}=8.92, p=$ 0.00059 ; condition*group: $F_{(4,42)}=1.33, p=0.28$; post hoc tests: males vs intact, $p=0.25$; males vs OVX, $p=$ 0.028 ; intact vs OVX, $p=0.93$, Bonferroni corrected), meal frequency decreased during the shock period similarly from baseline across all groups (Fig. $3 B$; group: $F_{(2,21)}$ $=0.61, p=0.55$; condition: $F_{(2,42)}=8.39, p=0.00086$; condition*group: $F_{(2,42)}=1.04, p=0.40$ ). However, males specifically increased the mean size of each meal obtained during the shock period (Fig. $3 C, D$ ), whereas the meal sizes of intact and OVX females decreased during shock (raw data: group: $F_{(2,21)}=3.04, p=0.070$; condition: $F_{(2,42)}=14.94, p=0.000013$; condition*group: $F_{(4,42)}$ $=4.95, p=0.0023$; post hoc tests: Baseline: males vs intact, $p=1.00$; males vs OVX, $p=0.36$; intact vs OVX, $p=0.087$; Shock: males vs intact, $p=0.028$; males vs OVX, $p=0.37$; intact vs OVX, $p=0.67$; Extinction: males vs intact, $p=1.00$; males vs OVX, $p=0.34$; intact vs OVX, 

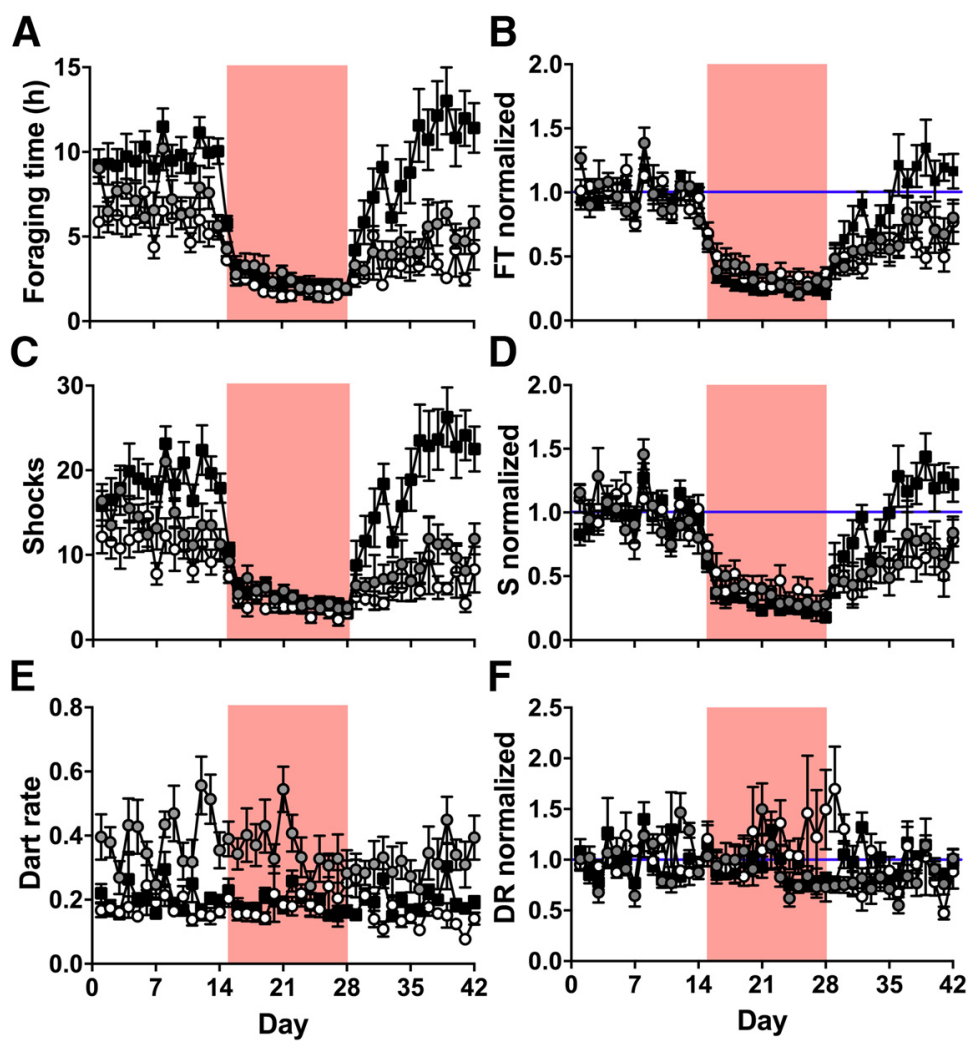

-o Females-Intact - - Females-OVX $\rightarrow$ - Males

Figure 4. Sex differences and effects of ovariectomy and footshocks on defensive behaviors. $\boldsymbol{A}, \boldsymbol{B}$, Mean daily $(\boldsymbol{A})$ and normalized (B; percentage of baseline average) time spent in the foraging area (percentage of total time; FT); $\boldsymbol{C}, \boldsymbol{D}$, mean daily (C) and normalized $(\boldsymbol{D})$ expected (during baseline and extinction) and actual (during shock) number of shocks received (S). $\boldsymbol{E}, \boldsymbol{F}$, mean daily $(\boldsymbol{E})$ and normalized $(\boldsymbol{F})$ dart rate (in darts/min; DR). Gray circles represent intact female rats $(n=8)$, open circles represent OVX female rats $(n=8)$, and black squares represent male rats $(n=8)$. Red background denotes shock period. All data represent the mean \pm SEM.

$p=0.048$; Bonferroni corrected; normalized data: group: $F_{(2,21)}=3.69, p=0.042$; condition: $F_{(2,42)}=12.59, p=$ 0.000052 ; condition*group: $F_{(4,42)}=4.06, p=0.0072$; post hoc tests: Shock: males vs intact, $p=0.018$; males vs OVX, $p=0.006$; intact vs OVX, $p=1.00$; Extinction: males vs intact, $p=1.00$; males vs OVX, $p=1.00$; intact vs OVX, $p=1.00$; Bonferroni corrected). After adjusting for baseline differences in body weight (Fig. 3E; group: $F_{(2,21)}=95.09, p=2.98 \mathrm{E}-11$; condition: $F_{(1.57,32.92)}=$ 111.92, $p=3.06 \mathrm{E}-14$, df adjusted; condition*group: $F_{(3.14 .32 .92)}=28.46, p=2.03 \mathrm{E}-9$, df adjusted), normalized growth rates (Fig. $3 F$ ) reveal that male rats are able to maintain a relatively stable growth trajectory compared to intact and OVX females (group: $F_{(2,21)}=4.69, p=0.021$; condition: $F_{(1.56,32.81)}=92.90, p=4.27 \mathrm{E}-13$, df adjusted; condition*group: $F_{3.13,32.81}=15.75, p=0.000001$, df adjusted; post hoc tests: Baseline: males vs intact, $p=$ 0.001 ; males vs OVX, $p=0.095$; intact vs OVX, $p=0.19$; Shock: males vs intact, $p=0.021$; males vs OVX, $p=$ 0.33 ; intact vs OVX, $p=60$; Extinction: males vs intact, $p$ $=0.001$; males vs OVX, $p=0.006$; intact vs OVX, $p=$ 1.00; Bonferroni corrected).

In terms of fear- and anxiety-related behaviors, although males spent more time foraging during baseline (Fig. 4A; group: $F_{(2,21)}=13.09, p=0.00020$; condition: $F_{(2,42)}=$
$70.13, p=4.11 \mathrm{E}-14 ;$ condition $*$ group: $F_{(4,42)}=7.40, p=$ 0.00013; post hoc tests: Baseline: males vs intact, $p=$ 0.080 ; males vs OVX, $p=0.0035$; intact vs OVX, $p=0.55$; Shock: males vs intact, $p=1.00$; males vs OVX, $p=0.26$; intact vs OVX, $p=0.29$; Extinction: males vs intact, $p=$ 0.0026 ; males vs OVX, $p=0.00019$; intact vs OVX, $p=$ 0.84; Bonferroni corrected), all groups exhibited similar reductions in the time spent in the foraging area following the introduction of footshocks (Fig. 4B; group: $F_{(2,21)}=$ $1.75, p=0.20$; condition: $F_{(1.31,27.43)}=128.23, p=6.38 \mathrm{E}-13$, df adjusted; condition*group: $F_{(2.61,27.43)}=6.55, p=$ 0.0025 , df adjusted; post hoc tests: Shock: males vs intact, $p=0.53$; males vs OVX, $p=0.32$; intact vs OVX, $p=1.00$; Extinction: males vs intact, $p=0.067$; males vs OVX, $p=0.024$; intact vs OVX, $p=1.00$; Bonferroni corrected). Figure $4 C$ shows the expected number of shocks rats would have received based on their naive, baseline foraging behavior, the actual mean number of shocks each group received during the shock condition (triggered randomly and unsignaled, $\sim 2 / h$ ), and the expected mean number of shocks they would have received based on their foraging behavior during extinction (no shock), demonstrating that while males spent more time in the foraging area during baseline, all rats quickly learned to avoid footshocks and received a similar num- 


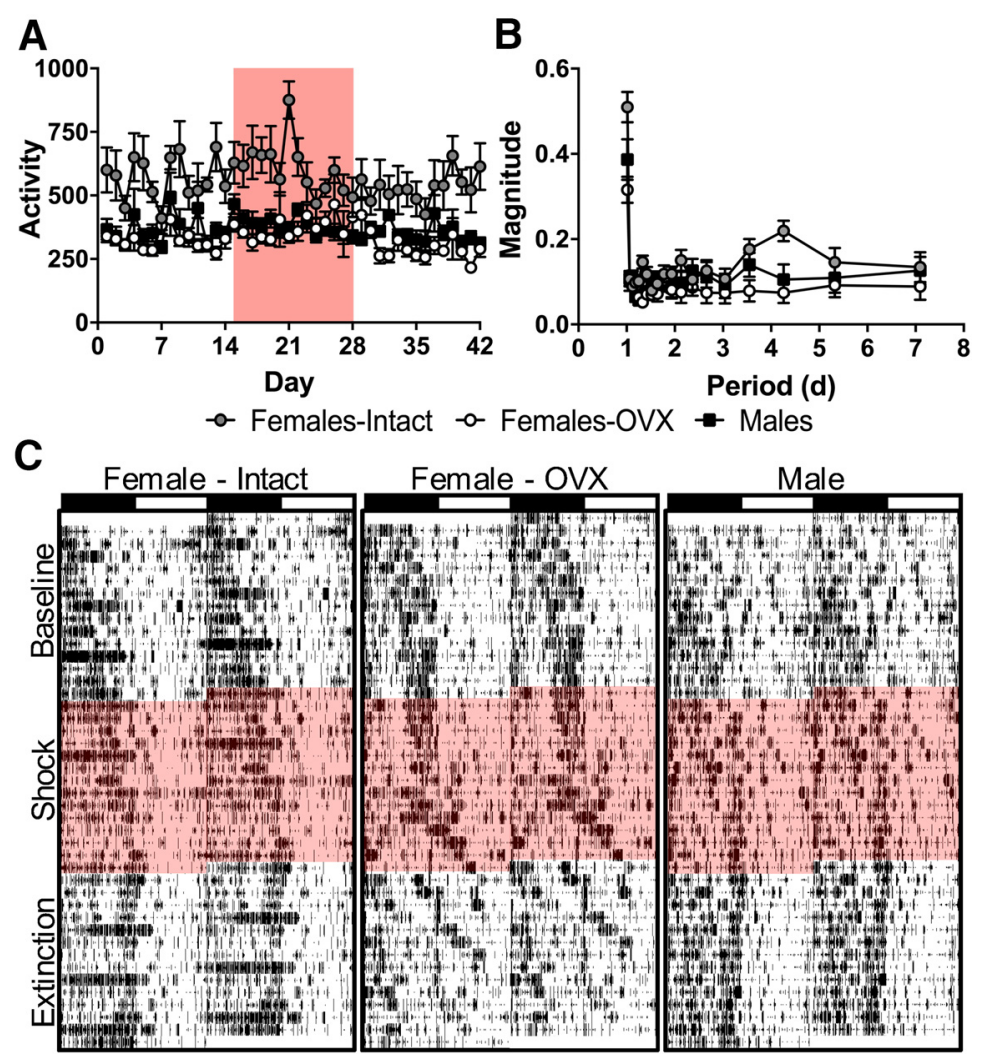

Figure 5. Sex differences and effects of ovariectomy and footshocks on general activity. $\boldsymbol{A}$, Mean daily activity (distance traveled, in meters). $\boldsymbol{B}$, Mean magnitude of component behavioral rhythms (converted to periods) derived via FFT of $1 \mathrm{~h}$ binned activity data (distance traveled, in meters) during baseline. Gray circles represent intact female rats $(n=8)$, open circles represent OVX female rats $(n=8)$, and black squares represent male rats $(n=8)$. All data represent the mean \pm SEM. $C$, Raster plots of activity $(1$ min bins) across all experiment days and conditions of representative intact female (left), OVX female (center), and male (right) rats. Red background denotes shock period.

ber of shocks during the shock period (group: $F_{(2,21)}=$ $14.08, p=0.00013$; condition: $F_{(2.42)}=59.23, p=5.96 \mathrm{E}-$ 13; condition*group: $F_{(4,42)}=8.00, p=0.000069$; post hoc tests: Baseline: males vs intact, $p=0.14$; males vs OVX, $p=0.0039$; intact vs OVX: $p=0.37$; Shock: males vs intact, $p=1.00$; males vs OVX, $p=0.27$; intact vs OVX, $p=0.26$; Extinction: males vs intact, $p=0.0013$; males vs OVX, $p=0.000099$; intact vs OVX, $p=0.87$; Bonferroni corrected). Furthermore, males extinguished this avoidance behavior at much faster rates than both intact and OVX female rats (Fig. $4 D$; group: $F_{(2,21)}=1.87, p=$ 0.18; condition: $F_{(1.44,30.23)}=96.38, p=1.95 \mathrm{E}-12$, df adjusted; condition*group: $F_{(2.88,30.23)}=7.26, p=0.00095$, df adjusted; post hoc tests: Shock: males vs intact, $p=$ 1.00; males vs OVX, $p=0.37$; intact vs OVX, $p=1.00$; Extinction: males vs intact, $p=0.029$; males vs OVX, $p=$ 0.021 ; intact vs OVX, $p=1.00$; Bonferroni corrected). Since it has recently been suggested that darting behavior-sudden activity bursts (exceeding $23.6 \mathrm{~cm} / \mathrm{s}$ ) -is a sexually dimorphic defensive behavior exhibited primarily by female rodents (Gruene et al., 2015), darting was examined throughout the present experiment in the same manner. While intact females displayed a greater number of darting episodes (Fig. 4E) than both males and OVX females during baseline (group: Baseline: $\chi^{2}{ }_{2}=13.55, p$ $=0.0011$; Shock: $\chi^{2}{ }_{2}=10.99, p=0.0041$ Extinction: $\chi^{2}{ }_{2}$
$=10.60, p=0.0050$, Kruskal-Wallis test; condition: $F_{(2,42)}$ $=4.32, p=0.020$; post hoc tests: males vs intact, $p=$ 0.024 ; males vs OVX, $p=0.59$; intact vs OVX, $p=0.011$; Dunnett T3 corrected), there was an overall reduction in darting behavior during the shock and extinction conditions, and there were no sex-specific changes across experimental conditions in darting behavior after adjusting for baseline differences, indicating that darting may not be a specific defensive behavior (Fig. 4F) (group: $F_{(2,21)}=$ $0.70, p=0.51$; condition: $F_{1.53,32.15}=2.00, p=0.16$, df adjusted; condition $*$ group: $F_{3.06,32.15}=1.20, p=0.33$, df adjusted).

Like darting, intact females demonstrated a greater level of general activity compared with both males and OVX females (Fig. 5A), which was relatively stable between groups and conditions (group: Baseline: $\chi^{2}{ }_{2}=$ 11.63, $p=0.0030$; Shock: $\chi_{2}^{2}=11.45, p=0.0033$; Extinction: $\chi^{2}{ }_{2}=12.89, p=0.0016$, Kruskal-Wallis test; condition: $F_{(2,42)}=7.67, p=0.0014$; post hoc tests: males vs intact, $p=0.018$; males vs OVX, $p=0.63$; intact vs OVX, $p=0.0074$; Dunnett T3 corrected), although there were significant, albeit small, changes in overall activity across shock and extinction from baseline (group: $F_{(2,21)}$ $=0.068, p=0.93$; condition: $F_{(2,42)}=7.51, p=0.0016$; condition*group: $\left.F_{(4,42)}=0.35, p=0.84\right)$. As other studies have found that the locomotor activity of females fluctu- 


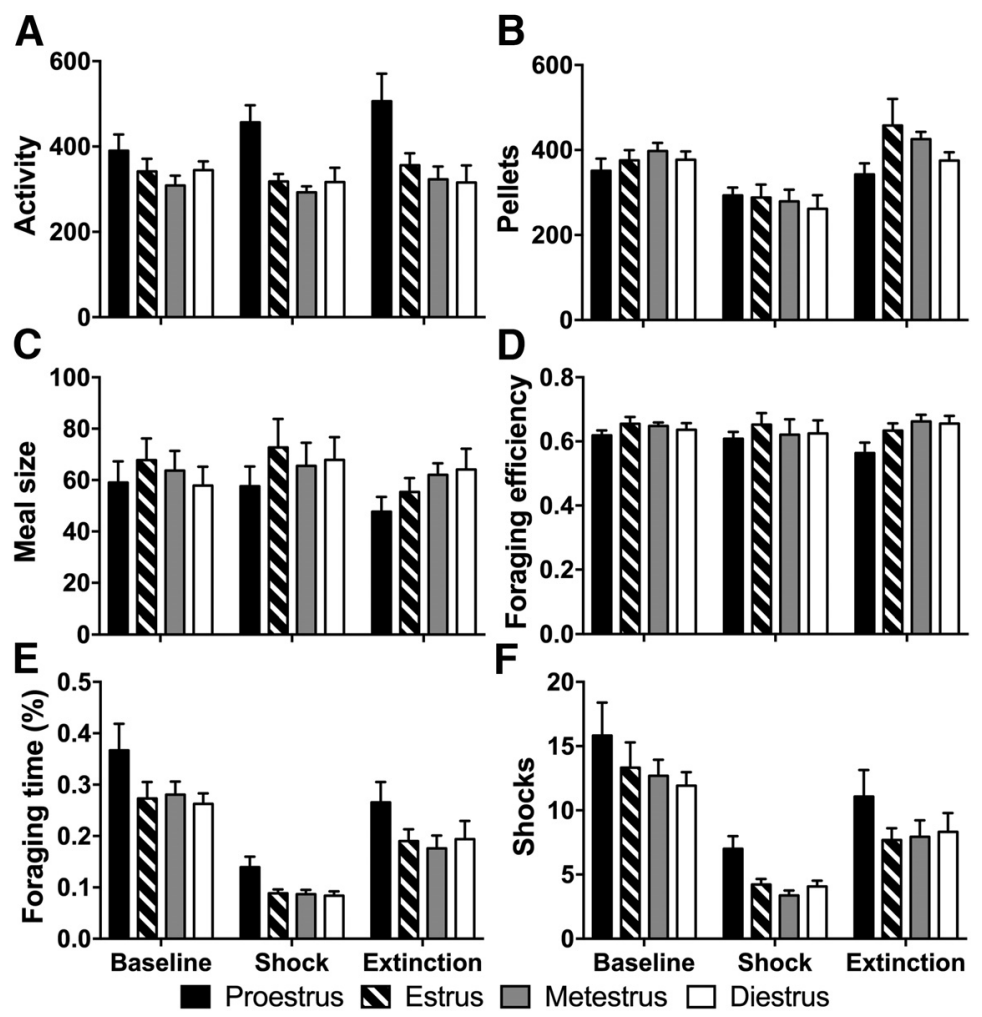

Figure 6. Effects of estrous phase on foraging and avoidance behaviors. A, Activity (distance traveled, in meters). $\boldsymbol{B}$, Number of pellets obtained. $\boldsymbol{C}$, Meal size (pellets/meal). $\boldsymbol{D}$, Foraging efficiency (pellets/lever press). $\boldsymbol{E}$, Time spent foraging (percentage of total time). $\boldsymbol{F}$, Expected (during baseline and extinction) and actual number of shocks (during shock) received during proestrus (black), estrus (striped), metestrus (gray), and diestrus (white) phases averaged within each condition (baseline, shock, extinction).

ates with their estrous cycle (Birke and Archer, 1975; Blizard et al., 1975; Frye et al., 2000), locomotor activity in the closed economy was examined for rhythmic fluctuations. A Fourier analysis of the locomotor behavior of rats was performed, and the magnitudes of the component frequencies in the 1-7 $d$ range were averaged by sex. As Figure $5 B$ shows, all groups exhibited normal circadian rhythms (1 d periods), but intact females uniquely exhibited a peak in the 3-5 d range, which corresponds to the normal period range of the estrous cycle ( $4.26 \mathrm{~d}$ period: intact vs males: $t_{(14)}=2.66, p=0.019$; intact vs OVX: $t_{(14)}=4.24, p=0.00083$; males vs OVX: $t_{(14)}=0.72, p=$ 0.49). Raster plots of a representative female (Fig. $5 C$ ) exemplify this periodic increase in locomotion, which is not seen in representative male or OVX female animals.

To determine how estrous phase may influence foraging and defensive behaviors, estrous phase was determined daily in a subset of the intact females $(n=4)$ via vaginal lavage. Behaviors were averaged across individual rats for each phase of the estrous cycle within each experimental condition. As suggested by the FFTs, locomotor activity was significantly influenced by the phase of estrous, with increases in locomotion being associated primarily with the proestrus phase [Fig. $6 A ; F_{(3,33)}=15.55$, $p<0.001$; Proestrus (P) vs Diestrus (D): $t_{(35)}=3.86, p<$ $0.001 ; \mathrm{P}$ vs Estrus $(\mathrm{E}): t_{(35)}=3.51, p=0.001 ; \mathrm{P}$ vs Metestrus (M): $\left.t_{(35)}=3.23, p=0.003\right]$. While there were no phase effects on the amount of food consumed (Fig. $6 B$ ) or the sizes of meals obtained (Fig. $6 C$ ) throughout the experiment, proestrous phase was associated with a significant reduction in foraging efficiency (Fig. $6 D ; F_{(3,33)}=$ $3.35, p=0.031$; P vs D: $t_{(37)}=2.43, p=0.020 ; \mathrm{P}$ vs E: $t_{(37)}$ $=3.12, p=0.003$; P vs M: $\left.t_{(37)}=3.02, p=0.005\right)$. Additionally, proestrus was associated with more time spent in the foraging zone (Fig. $6 E ; F_{(3,33)}=7.21, p=0.001$; $\mathrm{P}$ vs $\mathrm{D}: t_{(37)}=3.69, p=0.001 ; \mathrm{P}$ vs $\mathrm{E}: t_{(37)}=3.23, p=0.003$; $P$ vs $M: t_{(37)}=2.88, p=0.007$ ] and, subsequently, more shocks (Fig. $6 F ; F_{(3,33)}=4.48, p=0.010$; P vs D: $t_{(36)}=$ $3.32, p=0.002 ; \mathrm{P}$ vs E: $t_{(36)}=2.97, p=0.005 ; \mathrm{P}$ vs $\mathrm{M}: t_{(36)}$ $=2.62, p=0.013$ ). Thus, estrous phase does appear to influence risky foraging decisions, with increased risk taking associated with the proestrus phase, although this does not appear to be associated with an increase in gains (e.g., more food), but rather with a decrease in foraging efficiency.

\section{Discussion}

The current study indicates that fear and anxiety function differently with respect to foraging behavior in male and female rats living in a dynamic and risky environment. The risky closed economy experiment demonstrated that, while both males and females avoid unpredictable shock at the same rate, they appeared to do so by using different foraging strategies. Whereas males responded to danger by increasing their meal size to maintain their baseline foraging efficiency and baseline body weight, females instead sacrificed their metabolic needs and lost weight rather than risk encountering the threat of foot- 
shock. Thus, the present findings extend the previous findings of sexual dimorphisms in fear and anxiety behavior, where male rats spent more time out of cover in a novel environment than female rats (Jolles et al., 2015), and female rats were more reluctant to consume food pellets in a novel environment than male rats (Carrier and Kabbaj, 2013; Turner and Burne, 2014), to risky foraging behavior embodying the larger-scale spatiotemporal integration of information that animals rely on to function in natural environments.

Differences between intact and ovariectomized females were primarily limited to overall body weight and the amount of food consumed. OVX females obtained more pellets per meal than intact females and were less active overall. Their baseline behaviors were more equivalent to male behavior, but they were similarly affected by the presence of shock and exhibited similar extinction rates to that of the intact females. Importantly, it has been shown that the estrous cycle influences pain sensitivity and that ovariectomized female rats exhibit higher pain thresholds than intact female rats (Ji et al., 2003, 2006; Prusator and Greenwood-Van Meerveld, 2016). In the present study, intact and OVX females exhibited similar rates of avoidance and changes in meal patterns during the shock period. If the pain threshold differed between intact and OVX groups, this did not appear to influence the longterm behavioral response to shock, which corresponds to others' findings that lower pain thresholds do not necessarily translate to enhanced fear responses (Van Oyen et al., 1979; Kosten et al., 2006; Graham et al., 2009; Lehner et al., 2010; Schaap et al., 2013). The FFTs detected a significant difference in infradian range (3-5 d) periodicity between OVX and intact females, providing evidence that fluctuations in general activity are due to the estrous cycle. While the proestrus phase of the estrous cycle in intact females was associated with an increase in risky behavior and more shocks received during the shock period, this was met with a decrease in foraging efficiency. Thus, the function of proestrus-related modulation of risky behavior does not appear to be directed toward facilitating foraging needs, and instead may be more related to reproductive behaviors, as previously suggested (Archer, 1975; Morgan et al., 2004; Byrnes and Bridges, 2006). Although it is clear that ovarian hormones play a relatively small activational role in the day-to-day behavior of female rats, they may not need to be actively controlled in experimental studies of fear and anxiety if estrous phase-specific phenomenon are not of interest, as others have suggested (Prendergast et al., 2014), and may be measured indirectly in locomotor behavior in studies that use similar longitudinal measurement. It is well established that ovarian hormones are critical during early development (Beatty, 1979; van Haaren et al., 1990), and such organizational effects and their functional consequences for fear, anxiety, and foraging behavior should be examined in future studies.

The risky closed economy design is akin to a continual inhibitory avoidance situation wherein footshock is a diffuse, unpredictable threat associated with a specific place (the gridded foraging area), and avoidance of shock is dependent on the inhibition of movement into the dangerous area. The finding that females extinguish slower than males in the closed economy is contrary to previous findings in single-footshock inhibitory avoidance paradigms, which show that females are quicker to return to an area associated with shock than males (Van Oyen et al., 1979; Heinsbroek et al., 1988; Beatty et al., 2013). The simultaneous approach food-avoid footshock conflict and relatively uninterrupted, long-term behavioral assay in this experiment may explain this discrepancy, which suggests that traditional inhibitory avoidance paradigms might not adequately address important functional and temporal dynamics of fear and anxiety as they relate to natural behaviors. Furthermore, the sex differences in general activity and darting behaviors during baseline and their corresponding reductions during the shock period cast doubt on the validity of tests that depend largely on locomotion (or its absence, as in freezing) for examining fear and anxiety behavior, at least when the threat is relatively diffuse, such as in open field and elevated-plus maze tests. These studies have typically concluded that female rodents are less fearful than male rodents as females are more likely to enter the center of an open space or the open arms of the elevated plus maze (both interpreted as risky behaviors; Masur, 1972; Blizard et al., 1975; Johnston and File, 1991; Zimmerberg and Farley, 1993). As others have argued (Masur, 1972; Gray and Lalljee, 1974; Archer, 1975; Birke and Archer, 1975; Fernandes et al., 1999), greater locomotor activity in females appears to be more related to general metabolic factors, which ovarian hormones are known to influence (Campbell and Febbraio, 2001), rather than fear or anxiety. Finally, the current results provide a closer match to sex differences in fear and anxiety observed in humans compared with Pavlovian fear-conditioning paradigms. Thus, approach-avoidance conflict situations may be more relevant to translational approaches to studying pathological fear and anxiety.

What, then, is the basis of sex differences in risky foraging strategies? The fact that ovariectomy in adult female rats did not alter the risky foraging strategies they used suggests that such behaviors are prepared during development. Evolutionary-developmental theory suggests that male and female mammals can be expected to display divergent behaviors as they typically make different trade-offs regarding the maintenance of survival and reproduction (Kodric-Brown and Brown, 1987; Ellis et al., 2009; West-Eberhard, 2014). Females tend to allocate more bioenergetic effort toward offspring development (i.e., parenting), while males tend to allocate more effort toward reproducing, and the propensity of a male to take risks may facilitate a reproductively focused strategy by promoting the achievement of social dominance and gaining access to mates (Kodric-Brown and Brown, 1987; Steinberg, 2008; Jolles et al., 2015). That females exhibit an attenuation in fear and anxiety behaviors just before the estrus phase may be related to their evolutionary need to mate despite the potential violence commonly accompanying mating behavior in many animals (West-Eberhard, 2014). Indeed, the presence of males, or just their odor, has 
been shown to elicit a stress response in rats (Sorge et al., 2014; Shors et al., 2016). Thus, proestrus-related hormones may function to decrease female aversion to copulation, and its effects on fear learning in laboratory settings may be an artifact of such a function. Following this interpretation, it is reasonable that a motivational stimulus relating to reproduction, such as access to a mate, may reveal a different pattern of estrous-related changes in risky decision-making.

In summary, the closed economy approach used in this study allows for the simulation of threat contingencies that animals are likely to encounter in the wild. In contrast to fear-conditioning studies that have reported that male rats show greater conditioned fear responses than female rats, the present results indicate that when animals live for extended periods, largely undisturbed, in a semi-naturalistic environment, female rats are more reactive to environmental threats than male rats, which models anxiety and fear-related disorders in humans. Future studies may benefit from similar longitudinal approach-avoidance paradigms and diverse measures to explore threat situations and biological factors (e.g., putative fear circuitry) underlying sex differences in fear behavior.

\section{References}

Archer J (1975) Rodent sex differences in emotional and related behavior. Behav Biol 14:451-479. Medline

Beatty WW (1979) Gonadal hormones and sex differences in nonreproductive behaviors in rodents: organizational and activational influences. Horm Behav 12:112-163. Medline

Beatty WW, Gregoire KC, Parmiter LL (2013) Sex differences in retention of passive avoidance behavior in rats. Bull Psychon Soc 2:99-100. CrossRef

Becker JB, Prendergast BJ, Liang JW (2016) Female rats are not more variable than male rats: a meta-analysis of neuroscience studies. Biol Sex Differ 7:34. CrossRef Medline

Birke LIA, Archer J (1975) Open-field behaviour of oestrous and dioestrous rats: evidence against an "emotionality" interpretation. Anim Behav 23:509-512. Medline

Blizard DA, Lippman HR, Chen JJ (1975) Sex-differences in openfield behavior in rat-inductive and activational role of gonadal hormones. Physiol Behav 14:601-608. Medline

Brown TA, Antony MM, Barlow DH (1992) Psychometric properties of the Penn State Worry Questionnaire in a clinical anxiety disorders sample. Behav Res Ther 30:33-37. CrossRef

Byrnes EM, Bridges RS (2006) Reproductive experience alters anxiety-like behavior in the female rat. Horm Behav 50:70-76. CrossRef Medline

Campbell S, Febbraio M (2001) Effect of ovarian hormones on mitochondrial enzyme activity in the fat oxidation pathway of skeletal muscle. Am J Physiol Endocrinol Metab 281:E803-E808.

Carrier N, Kabbaj M (2013) Sex differences in the antidepressant-like effects of ketamine. Neuropharmacology 70:27-34. CrossRef Medline

Davis M (1992) The role of the amygdala in fear-potentiated startle: implications for animal models of anxiety. Trends Pharmacol Sci 13:35-41. Medline

Diaz-Veliz G, Soto V, Dussaubat N, Mora S (1989) Influence of the estrous cycle, ovariectomy and estradiol replacement upon the acquisition of conditioned avoidance responses in rats. Physiol Behav 46:397-401. Medline

Ellis BJ, Figueredo AJ, Brumbach BH, Schlomer GL (2009) Fundamental dimensions of environmental risk. Hum Nat 20:204-268. CrossRef Medline

Fanselow MS, Lester LS (1988) A functional behavioristic approach to aversively motivated behavior: predatory imminence as a de- terminant of the topography of defensive behavior. In: Evolution and learning (Beecher RC, Bolles MD, eds), pp 185-212. Hillsdale, NJ: Erlbaum.

Fernandes C, González MI, Wilson CA, File SE (1999) Factor analysis shows that female rat behaviour is characterized primarily by activity, male rats are driven by sex and anxiety. Pharmacol Biochem Be 64:731-736. Medline

Frye CA, Walf AA (2002) Changes in progesterone metabolites in the hippocampus can modulate open field and forced swim test behavior of proestrous rats. Horm Behav 41:306-315. CrossRef Medline

Frye CA, Petralia SM, Rhodes ME (2000) Estrous cycle and sex differences in performance on anxiety tasks coincide with increases in hippocampal progesterone and 3alpha,5alpha-THP. Pharmacol Biochem Behav 67:587-596. Medline

Geer JH (1965) The development of a scale to measure fear. Behav Res Ther 3:45-53. Medline

Gray JA, Lalljee B (1974) Sex differences in emotional behaviour in the rat: correlation between open-field defecation and active avoidance. Anim Behav 22:856-861. Medline

Graham LK, Yoon T, Lee HJ, Kim JJ (2009) Strain and sex differences in fear conditioning: $22 \mathrm{kHz}$ ultrasonic vocalizations and freezing in rats. Psychol Neurosci 2:219-225. CrossRef

Gruene TM, Flick K, Stefano A, Shea SD, Shansky RM (2015) Sexually divergent expression of active and passive conditioned fear responses in rats. Elife 4:e11352. CrossRef

Gullone E (2000) The development of normal fear: a century of research. Clin Psychol Rev 20:429-451. Medline

Gupta RR, Sen S, Diepenhorst LL, Rudick CN, Maren S (2001) Estrogen modulates sexually dimorphic contextual fear conditioning and hippocampal long-term potentiation (LTP) in rats. Brain Res 888:356-365. Medline

Heinsbroek RPW, van Haaren F, van de Poll NE (1988) Sex differences in passive avoidance behavior of rats: sex-dependent susceptibility to shock-induced behavioral depression. Physiol Behav 43:201-206. CrossRef

Helmstetter FJ, Fanselow MS (1993) Aversively motivated changes in meal patterns of rats in a closed economy: the effects of shock density. Anim Learn Behav 21:168-175. CrossRef

Hursh SR (1980) Economic concepts for the analysis of behavior. J Exp Anal Behav 34:219-238. Medline

Institute of Medicine (2014) Treatment for posttraumatic stress disorder in military and veteran populations: final assessment. Washington, DC: National Academies.

Ji Y, Murphy AZ, Traub RJ (2003) Estrogen modulates the visceromotor reflex and responses of spinal dorsal horn neurons to colorectal stimulation in the rat. J Neurosci 23:3908-3915.

Ji Y, Murphy AZ, Traub RJ (2006) Sex differences in morphineinduced analgesia of visceral pain are supraspinally and peripherally mediated. Am J Physiol Regul Integr Comp Physiol 291:R307R314. CrossRef Medline

Johnston AL, File SE (1991) Sex differences in animal tests of anxiety. Physiol Behav 49:245-250. Medline

Jolles JW, Boogert NJ, van den Bos R (2015) Sex differences in risk-taking and associative learning in rats. $\mathrm{R}$ Soc Open Sci 2:150485. CrossRef Medline

Jones CE, Monfils M-H (2016) Fight, flight, or freeze? The answer may depend on your sex. Trends Neurosci 39:51-53. CrossRef Medline

Kessler RC, Berglund P, Demler O, Jin R, Merikangas KR, Walters EE (2005) Lifetime prevalence and age-of-onset distributions of DSM-IV disorders in the National Comorbidity Survey replication. Arch Gen Psychiatry 62:593-602. CrossRef Medline

Kim E, Kim EJ, Yeh R, Shin M, Bobman J, Krasne FB, Kim JJ (2014) Amygdaloid and non-amygdaloid fear both influence avoidance of risky foraging in hungry rats. Proc Biol Sci 281:20133357. CrossRef

Kodric-Brown A, Brown JH (1987) Anisogamy, sexual selection, and the evolution and maintenance of sex. Evol Ecol 1:95-105. CrossRef 
Kosten TA, Lee HJ, Kim JJ (2006) Early life stress impairs fear conditioning in adult male and female rats. Brain Res 1087:142150. CrossRef

Lehner M, Wisłowska-Stanek A, Krzaścik P, Maciejak P, Szyndler J, Płaźnik A (2010) The relationship between pain sensitivity and conditioned fear response in rats. Acta Neurobiol Exp (Wars) 70:56-66. Medline

Lima SL, Dill LM (1990) Behavioral decisions made under the risk of predation: a review and prospectus. Can J Zool 68:619-640. CrossRef

Lissek S, Powers AS, McClure EB, Phelps EA, Woldehawariat G, Grillon C, Pine DS (2005) Classical fear conditioning in the anxiety disorders: a meta-analysis. Behav Res Ther 43:1391-1424. CrossRef Medline

Marcondes FK, Miguel KJ, Melo LL, Spadari-Bratfisch RC (2001) Estrous cycle influences the response of female rats in the elevated plus-maze test. Physiol Behav 74:435-440. Medline

Marcondes FK, Bianchi FJ, Tanno AP (2002) Determination of the estrous cycle phases of rats: some helpful considerations. Braz J Biol 62:609-614. Medline

Maren S, De Oca B, Fanselow MS (1994) Sex differences in hippocampal long-term potentiation (LTP) and Pavlovian fear conditioning in rats: positive correlation between LTP and contextual learning. Brain Res 661:25-34. Medline

Markus EJ, Zecevic M (1997) Sex differences and estrous cycle changes in hippocampus-dependent fear conditioning. Psychobiology 25:246-252.

Masur J (1972) Sex differences in "emotionality" and behavior of rats in the open-field. Behav Biol 7:749-754. Medline

McLean CP, Anderson ER (2009) Brave men and timid women? A review of the gender differences in fear and anxiety. Clin Psychol Rev 29:496-505. CrossRef Medline

Milad MR, Quirk GJ (2012) Fear extinction as a model for translational neuroscience: ten years of progress. Annu Rev Psychol 63:129-151. CrossRef Medline

Milad MR, Igoe SA, Lebron-Milad K, Novales JE (2009) Estrous cycle phase and gonadal hormones influence conditioned fear extinction. Neuroscience 164:887-895. CrossRef Medline

Monies G, Luque E (1988) Effects of ovarian steroids on vaginal smears in the rat. Cells Tissues Organs 133:192-199. Medline

Mora S, Dussaubat N, Díaz-Véliz G (1996) Effects of the estrous cycle and ovarian hormones on behavioral indices of anxiety in female rats. Psychoneuroendocrinology 21:609-620. Medline

Morgan MA, Schulkin J, Pfaff DW (2004) Estrogens and nonreproductive behaviors related to activity and fear. Neurosci Biobehav Rev 28:55-63. CrossRef Medline

Ollendick TH, King NJ, Frary RB (1989) Fears in children and adolescents: reliability and generalizability across gender, age and nationality. Behav Res Ther 27:19-26. Medline

Pawluski JL, Brummelte S, Barha CK, Crozier TM, Galea LA (2009) Effects of steroid hormones on neurogenesis in the hippocampus of the adult female rodent during the estrous cycle, pregnancy, lactation and aging. Front Neuroendocrinol 30:343-357. CrossRef Medline

Pellman BA, Kim E, Reilly M, Kashima J, Motch O, de la Iglesia HO, Kim JJ (2015) Time-specific fear acts as a non-photic entraining stimulus of circadian rhythms in rats. Sci Rep 5:14916. CrossRef Medline

Prendergast BJ, Onishi KG, Zucker I (2014) Female mice liberated for inclusion in neuroscience and biomedical research. Neurosci Biobehav Rev 40:1-5. CrossRef Medline

Prusator DK, Greenwood-Van Meerveld B (2016) Sex-related differences in pain behaviors following three early life stress paradigms. Biol Sex Differ 7:29 CrossRef Medline

Rasia-Filho AA, Haas D, de Oliveira AP, de Castilhos J, Frey R, Stein D, Lazzari VM, Back F, Pires GN, Pavesi E, Winkelmann-Duarte EC, Giovenardi M (2012) Morphological and functional features of the sex steroid-responsive posterodorsal medial amygdala of adult rats. Mini Rev Med Chem 12:1090-1106. Medline

Schaap MW, van Oostrom H, Doornenbal A, van 't Klooster J, Baars AM, Arndt SS, Hellebrekers LJ (2013) Nociception and conditioned fear in rats: strains matter. PLoS One 8:e83339. CrossRef Medline Shansky R, Glavis-Bloom C, Lerman D, McRae P, Benson C, Miller K, Cosand L, Horvath T, Arnsten A (2004) Estrogen mediates sex differences in stress-induced prefrontal cortex dysfunction. Mol Psychiatry 9:531-538. CrossRef Medline

Shors TJ, Tobón K, DiFeo G, Durham DM, Chang HYM (2016) Sexual Conspecific Aggressive Response (SCAR): a model of sexual trauma that disrupts maternal learning and plasticity in the female brain. Sci Rep 6:18960. CrossRef

Sorge RE, Martin LJ, Isbester KA, Sotocinal SG, Rosen S, Tuttle AH, Wieskopf JS, Acland EL, Dokova A, Kadoura B, Leger P, Mapplebeck JC, McPhail M, Delaney A, Wigerblad G, Schumann AP, Quinn T, Frasnelli J, Svensson Cl, Sternberg WF, et al. (2014) Olfactory exposure to males, including men, causes stress and related analgesia in rodents. Nat Methods 11:629-632. CrossRef Medline

Steinberg $L$ (2008) A social neuroscience perspective on adolescent risk-taking. Dev Rev 28:78-106. CrossRef Medline

Turner KM, Burne TH (2014) Comprehensive behavioural analysis of Long Evans and Sprague-Dawley rats reveals differential effects of housing conditions on tests relevant to neuropsychiatric disorders. PLoS One 9:e93411. CrossRef

van Haaren F, van Hest A, Heinsbroek RPW (1990) Behavioral differences between male and female rats: effects of gonadal hormones on learning and memory. Neurosci Biobehav Rev 14:23-33. Medline

Van Oyen HG, Van de Poll NE, De Bruin JPC (1979) Sex, age and shock-intensity as factors in passive avoidance. Physiol Behav 23:915-918. Medline

West-Eberhard MJ (2014) Darwin's forgotten idea: the social essence of sexual selection. Neurosci Biobehav Rev 46:501-508. CrossRef

Woolley CS, McEwen BS (1992) Estradiol mediates fluctuation in hippocampal synapse density during the estrous cycle in the adult rat. J Neurosci 12:2549-2554. CrossRef

Zimmerberg B, Farley MJ (1993) Sex differences in anxiety behavior in rats: role of gonadal hormones. Physiol Behav 54:1119-1124. Medline

Zucker I, Beery AK (2010) Males still dominate animal studies. Nature 465:690-690. CrossRef Medline 